\title{
Optimization and Prediction of Ultimate Tensile Strength in Metal Active Gas Welding
}

\author{
Anusit Ampaiboon, On-Uma Lasunon, and Bopit Bubphachot \\ Manufacturing and Materials Research Unit, Faculty of Engineering, Mahasarakham University, Maha Sarakham 44150, Thailand \\ Correspondence should be addressed to On-Uma Lasunon; onuma.1@msu.ac.th
}

Received 15 June 2015; Accepted 1 September 2015

Academic Editor: Stefano Curcio

Copyright ( 2015 Anusit Ampaiboon et al. This is an open access article distributed under the Creative Commons Attribution License, which permits unrestricted use, distribution, and reproduction in any medium, provided the original work is properly cited.

We investigated the effect of welding parameters on ultimate tensile strength of structural steel, ST37-2, welded by Metal Active Gas welding. A fractional factorial design was used for determining the significance of six parameters: wire feed rate, welding voltage, welding speed, travel angle, tip-to-work distance, and shielded gas flow rate. A regression model to predict ultimate tensile strength was developed. Finally, we verified optimization of the process parameters experimentally. We achieved an optimum tensile strength $(558 \mathrm{MPa})$ and wire feed rate, $19 \mathrm{~m} / \mathrm{min}$, had the greatest effect, followed by tip-to-work distance, $7 \mathrm{~mm}$, welding speed, $200 \mathrm{~mm} / \mathrm{min}$, welding voltage, $30 \mathrm{~V}$, and travel angle, $60^{\circ}$. Shield gas flow rate, $10 \mathrm{~L} / \mathrm{min}$, was slightly better but had little effect in the $10-20 \mathrm{~L} / \mathrm{min}$ range. Tests showed that our regression model was able to predict the ultimate tensile strength within $4 \%$.

\section{Introduction}

Metal Active Gas (MAG) welding process, a subtype of Gas Metal Arc Welding (GMAW), has been used in welding industry for many decades due to its significant advantages, including high productivity, simple mechanism, good quality and mechanical properties of weld joint, and wide range of weldable materials and filler metals [1]. In MAG welding, a DC electric arc forms between a continuous filler electrode and a base metal. Heat is generated to fuse the metal in the joint area. Active shielding gas protects the molten weld pools and the electrode wire from contaminants in the atmosphere $[1,2]$.

In any welding process, welding parameters play important role in product quality as they affect mechanical properties and weld joint geometry [1-4]. However, selection of optimal parameters to meet the required specification is complicated as the weld quality can be affected by several variables, such as chemical compositions of workpiece material and wire electrode, shielding gas, and any heat treatment $[1,5]$. Moreover, experimental optimization by trial and error is very time-consuming and costly $[3,4$, 6]. Consequently, several methods and approaches such as Design of Experiment (DoE) and statistical techniques have been used to overcome this problem $[1-3,6]$. Among the various methods used, a fractional factorial design has been widely used to identify significant process parameters and optimize product quality as it is useful for modelling and analyzing problems involving several parameters [7]. Several research studies have focused on optimizing welded bead geometry and weld joint mechanical properties [1-6, 8].

In this work, the fractional factorial design was used to determine the effect of MAG welding parameters on ultimate tensile strength (UTS) of mild steel. Tensile strength was selected to assess weld quality because it is a key mechanical property that can describe weld joint performance [6]. The UTS of weld joint is important because it is an estimate of the maximum load that the weld can support [5]. The optimal parameters for maximum UTS were also considered. Analysis of variance (ANOVA) and regression analysis were used to determine the significant parameters and to develop a model for the UTS.

\section{Experimental Details}

2.1. Specimen Preparation and Testing. Mild steel (ST372) $6 \mathrm{~mm}$ thick was the base metal; it has yield strength 


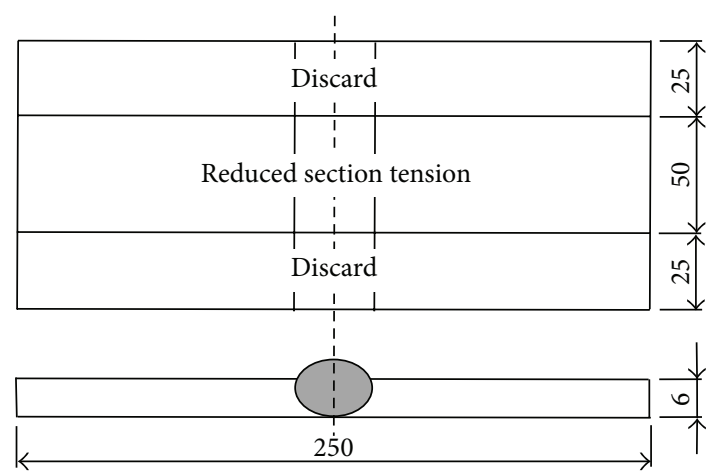

(a)

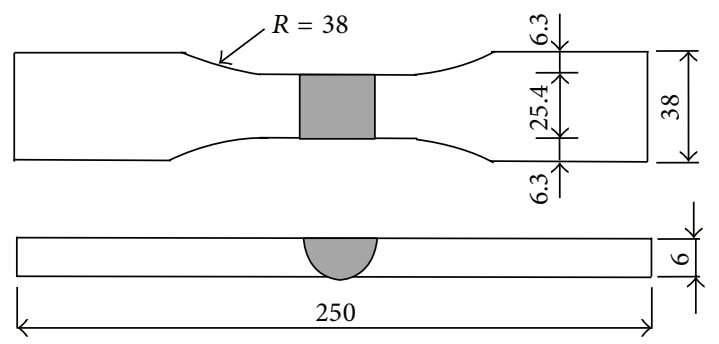

(b)

FIGURE 1: Schematic diagram of (a) zero-gap butt joint welding and (b) tensile strength test sample (unit: $\mathrm{mm}$ ).

TABLE 1: Chemical compositions of base metal and electrode wire (\% weight).

\begin{tabular}{lcccccc}
\hline Material & $\mathrm{S}$ & $\mathrm{Si}$ & $\mathrm{Mn}$ & $\mathrm{C}$ & $\mathrm{P}$ & $\mathrm{Fe}$ \\
\hline ST37-2 base metal & 0.003 & 0.04 & 0.82 & 0.12 & 0.012 & Balance \\
ER70S-6 electrode & 0.01 & 0.58 & 1.15 & 0.08 & 0.014 & Balance \\
\hline
\end{tabular}

of $340 \mathrm{MPa}$ and ultimate tensile strength of $470 \mathrm{MPa}$ : its chemical composition is shown in Table $1.125 \mathrm{~mm} \times 100 \mathrm{~mm}$ specimens were prepared and cleaned with a brush for better weld quality. A zero-gap butt joint was formed in a single pass by MAG welding; see Figure 1(a). After welding, samples for ultimate tensile strength (UTS) test were cut in accordance with the ASME IX standard; see Figure 1(b). The UTS was tested at room temperature using a 10-ton capability universal testing machine.

2.2. Equipment. A WIM welding machine MIG 350SEF, with constant voltage power source and direct current electrode positive (DCEP) polarity was used for welding. An electrode wire, AWS A5.18 ER70S-6, with $0.8 \mathrm{~mm}$ rod diameter was the welding consumable. Chemical composition of this electrode is shown in Table 1. Commercial carbon dioxide (99.98\% $\mathrm{CO}_{2}$ ) was used as the shielding gas to prevent chemical reactions between the hot workpiece surface and the atmosphere.

2.3. Selection of Welding Parameters and Their Levels. Six input parameters were investigated with feasible ranges recommended by a welding handbook [9] and limited by

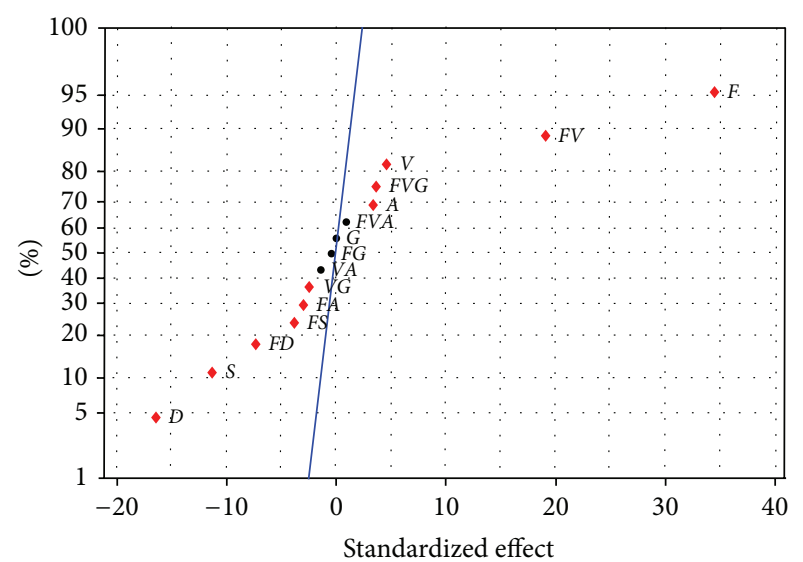

Effect type

- Not significant

$\checkmark$ Significant

Figure 2: Normal probability plot of the effects (at $\alpha=0.05$ ).

the machine capabilities. The two levels of the input factors used are shown in Table 2.

2.4. Experimental Design. The experiment used a $2^{6-2}$ fractional factorial design with 16 combinations. Two replicates were run for each combination, giving a total of $2 \times 16=$ 32 experiments. The experimental layout was generated by MINITAB software [10] where systematic error was avoided by random parameter assignment; see Table 3.

\section{Result and Discussion}

3.1. Experimental Result. Table 3 shows our results. The statistical software, MINITAB, analyzed the data and generated the model for the UTS.

3.2. Analysis of Variance for UTS. A normal probability plot of the effects in Figure 2 was used to visually identify important effects on the UTS. Important effects are large and further from the fitted line while unimportant effects are smaller and centered around zero [7, 10]. In Figure 2, the significant effects that emerge from this analysis are the strong effect of $F, V, S, A$ and $D$; the 2-way interactions, $F D, F S, F A, F V$, and $V G$, and the 3 -way interaction, FVG. The insignificant effects are the weak effect of $G$ and the interactions $F G, V A$, and FVA. All of the insignificant effects should be removed from the analysis, but weak effects should not be removed when they are involved in significant interactions [8]. Therefore, the weak effect $G$ is included in the model due to its significant interactions ( $V G$ and $F V G$ ).

After the insignificant terms were removed, the significance of the reduced UTS model was tested; see Table 4. The estimated effects and the coefficients of the reduced model are also given in Table 4. A higher absolute value of the estimated effect indicates a greater influence of that model term on the UTS. Consequently, it was evident that wire feed rate $(F)$ showed the greatest effect on the UTS of weld joint, followed 
TABLE 2: Welding input parameters and their levels.

\begin{tabular}{lccccc}
\hline Number & Parameter & Unit & Notation & Low level $(-1)$ & High level $(+1)$ \\
\hline 1 & Wire feed rate & $\mathrm{m} / \mathrm{min}$ & $F$ & 7 & 20 \\
2 & Volt & $V$ & $S$ & 200 & 30 \\
3 & Welding voltage & $\mathrm{mm} / \mathrm{min}$ & $A$ & 60 & 500 \\
4 & Welding speed & Degree & $D$ & 7 & 80 \\
5 & Travel angle & $\mathrm{mm}$ & $G$ & 10 & 20 \\
6 & Tip-to-work distance & Liter/min & & 15 \\
\hline
\end{tabular}

TABLE 3: Experimental design matrix and results.

\begin{tabular}{lccccccccccccccc}
\hline Run order & $F$ & $V$ & $S$ & $A$ & $D$ & $G$ & UTS [MPa] & Run order & $F$ & $V$ & $S$ & $A$ & $D$ & $G$ & UTS [MPa] \\
\hline 1 & 1 & -1 & 1 & -1 & -1 & 1 & 173 & 17 & 1 & 1 & -1 & 1 & -1 & -1 & 211 \\
2 & 1 & 1 & -1 & -1 & -1 & 1 & 265 & 18 & 1 & -1 & -1 & 1 & 1 & 1 & 250 \\
3 & -1 & -1 & -1 & -1 & -1 & -1 & 57 & 19 & -1 & -1 & 1 & -1 & 1 & 1 & 73 \\
4 & 1 & -1 & 1 & 1 & -1 & -1 & 533 & 20 & -1 & -1 & -1 & -1 & -1 & -1 & 549 \\
5 & -1 & 1 & 1 & 1 & -1 & 1 & 124 & 21 & 1 & 1 & -1 & 1 & -1 & -1 & 137 \\
6 & 1 & 1 & 1 & 1 & 1 & 1 & 278 & 22 & -1 & 1 & -1 & -1 & 1 & 1 & 325 \\
7 & -1 & 1 & -1 & -1 & 1 & 1 & 124 & 23 & -1 & -1 & 1 & 1 & 1 & -1 & 93 \\
8 & 1 & -1 & 1 & 1 & -1 & -1 & 306 & 24 & -1 & -1 & 1 & -1 & 1 & 1 & 306 \\
9 & 1 & -1 & -1 & -1 & 1 & -1 & 307 & 25 & -1 & 1 & 1 & -1 & -1 & -1 & 264 \\
10 & 1 & -1 & -1 & -1 & 1 & -1 & 246 & 26 & 1 & -1 & -1 & 1 & 1 & 1 & 263 \\
11 & 1 & 1 & 1 & -1 & 1 & -1 & 122 & 27 & -1 & -1 & -1 & 1 & -1 & 1 & 124 \\
12 & 1 & 1 & 1 & 1 & 1 & 1 & 551 & 28 & -1 & 1 & -1 & 1 & 1 & -1 & 537 \\
13 & -1 & -1 & 1 & 1 & 1 & -1 & 151 & 29 & -1 & 1 & 1 & -1 & -1 & -1 & 135 \\
14 & -1 & 1 & 1 & 1 & -1 & 1 & 312 & 30 & 1 & 1 & 1 & -1 & 1 & -1 & 321 \\
15 & -1 & 1 & -1 & 1 & 1 & -1 & 118 & 31 & 1 & 1 & -1 & -1 & -1 & 1 \\
16 & 1 & -1 & 1 & -1 & -1 & 1 & 318 & 32 & -1 & -1 & -1 & 1 & -1 & 1 & 30 \\
\hline
\end{tabular}

TABLE 4: Estimated effects and coefficients for UTS (coded units).

\begin{tabular}{lcccc}
\hline Term & Effect & Coefficient & $t$-statistic & $p$ value \\
\hline Constant & & 248.69 & 80.45 & $<0.001$ \\
Wire feed rate, $F$ & 210.751 & 105.38 & 34.09 & $<0.001$ \\
Welding voltage, $V$ & 27.12 & 13.56 & 4.39 & $<0.001$ \\
Welding speed, $S$ & -68.13 & -34.06 & -11.02 & $<0.001$ \\
Travel angle, $A$ & 22.00 & 11.00 & 3.56 & 0.002 \\
Tip-to-work distance, $D$ & -99.50 & -49.75 & -16.09 & $<0.001$ \\
Shield gas flow rate, $G$ & -0.25 & -0.13 & -0.04 & 0.968 \\
$F V$ & 116.00 & 58.00 & 18.76 & $<0.001$ \\
$F S$ & -22.00 & -11.00 & -3.56 & 0.002 \\
$F A$ & -16.63 & -8.31 & -2.69 & 0.015 \\
$F D$ & -43.63 & -21.81 & -7.06 & $<0.001$ \\
$V G$ & -16.00 & -8.00 & -2.59 & 0.018 \\
$F V G$ & 21.12 & 10.56 & 3.42 & 0.003 \\
\hline
\end{tabular}

$S=17.4857 R^{2}=99.07 \% R^{2}$ (adj.) $=98.48 \%$, coefficient standard error $=3.1$.

by interaction of wire feed rate and welding voltage $(F V)$, tipto-work distance $(D)$, welding speed $(S)$, interaction of wire feed rate and tip-to-work distance $(F D)$, welding voltage $(V)$, interaction of wire feed rate and welding speed $(F S)$, 3-way interaction of wire feed rate-welding voltage and shielding gas flow rate $(F V G)$, travel angle $(A)$, interaction of wire feed rate and travel angle $(F A)$, interaction of welding voltage and gas flow rate $(V G)$, and shielding gas flow rate $(G)$, respectively. This conclusion was graphically presented in Figure 2. The extremely low $p$ value, much less than 0.05 , implied that the model term was highly significant. The coefficient of determination, $R^{2}$, of 0.9907 was in reasonable agreement with the adjusted $R^{2}$ of 0.9848 . Therefore, the reduced model terms appeared to be statistically adequate to develop the prediction model for the UTS.

3.3. Model for UTS. Multiple regression analysis for the prediction of UTS was conducted on the experimental data in Table 3. The regression model (uncoded units) in (1) was developed by calculating regression coefficients of the reduced model terms:

$$
\begin{aligned}
\mathrm{UTS}_{\text {(un-coded unit) }}= & 288.912-6.79774 F-17.5458 V \\
& -0.0681944 S+2.90104 A \\
& -0.62240 D+7.97500 G \\
& +1.92756 F * V-0.0122222 F * S \\
& -0.138542 F * A-0.908854 F * D \\
& -0.325 V * G+0.00038462 F * V \\
& * G,
\end{aligned}
$$


TABLE 5: Results of confirmation experiment for UTS.

\begin{tabular}{|c|c|c|c|c|c|c|c|c|}
\hline Experiment number & Number 1 & Number 2 & Number 3 & Number 4 & Number 5 & Number 6 & Mean & SD \\
\hline Actual value [MPa] & 541 & 537 & 564 & 564 & 569 & 575 & 558.3 & 15.6 \\
\hline Predicted value [MPa] & 553 & 553 & 553 & 553 & 553 & 553 & & \\
\hline$\%$ Error $^{*}$ & -2 & -3 & 2 & 2 & 3 & 4 & & \\
\hline
\end{tabular}

${ }^{*}$ Percentage error was calculated as $\%$ Error $=(($ Actual value - Predicted value $) * 100) /$ Predicted value.
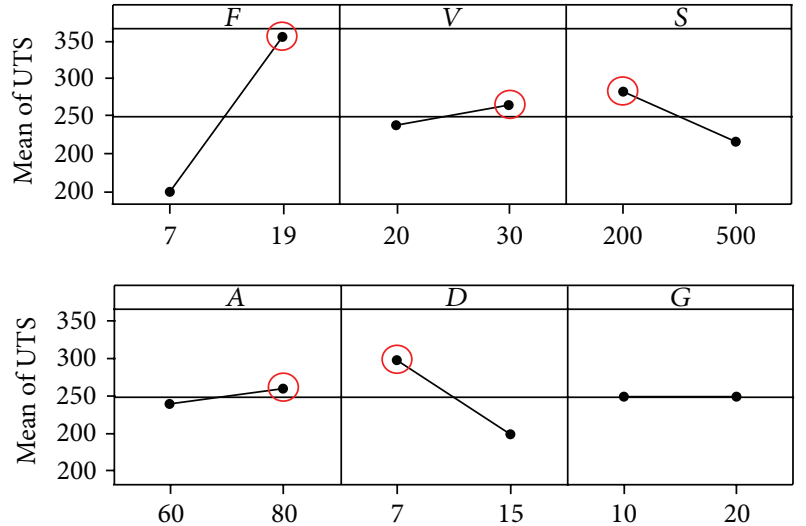

(a)
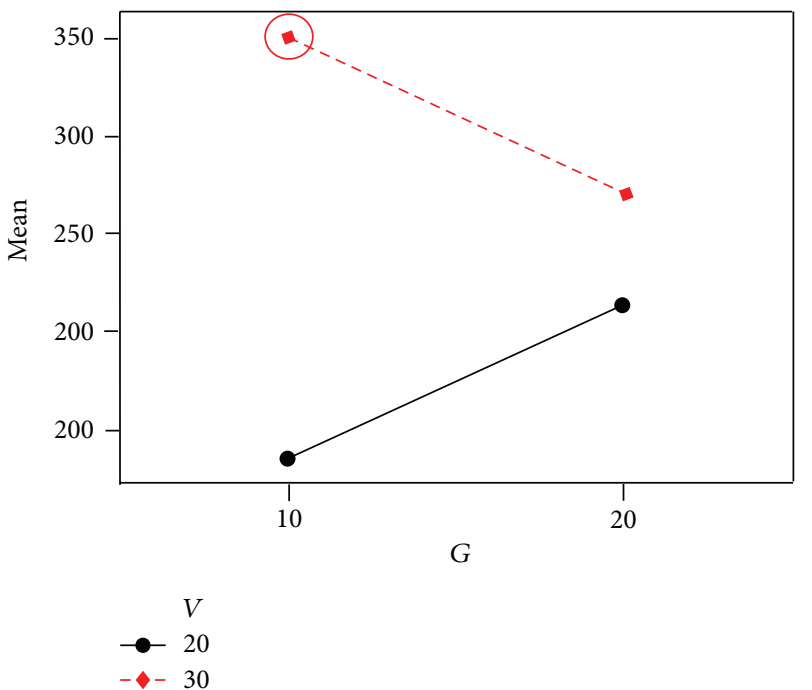

(b)

FIGURE 3: (a) Main effects plot and (b) interaction plot of welding voltage and gas flow rate $(V G)$ for UTS.

where UTS is ultimate tensile strength $(\mathrm{MPa}), F$ is wire feed rate $(\mathrm{m} / \mathrm{min}), V$ is welding voltage (volt), $S$ is welding speed ( $\mathrm{mm} / \mathrm{min}), A$ is travel angle (degree), $D$ is tip-to-work distance $(\mathrm{mm})$, and $G$ is shielded gas flow rate (liter/min).

In running a two-level factorial experiment, we usually fit a first-order model which includes only the main effects and interaction terms [7]; see (1).

3.4. UTS Optimization of Welding Parameters. The maximum UTS was the single objective of this study. To select the optimal welding parameters, the main effect of each parameter in Figure 3(a) was considered. Figure 3(a) revealed that wire feed rate $(F)$, welding voltage $(V)$, and travel angle $(A)$ had positive effects on the UTS and increasing these variables leads to larger UTS. In contrast, welding speed $(S)$ and tip-to-work distance $(D)$ had negative effects-increasing these variables reduced the UTS. Shield gas flow rate $(G)$ within the $10-20 \mathrm{~L} / \mathrm{min}$ range showed less effect; thus the significant VG interaction plot was used to determine the optimum condition. Figure 3 (b) showed that welding voltage had a large effect at low gas flow rate, but smaller effect at high gas flow rate. As the maximum UTS was desired, the optimum process parameters for MAG welding were wire feed rate at $19 \mathrm{~m} / \mathrm{min}$, welding voltage at 30 volts, welding speed at $200 \mathrm{~mm} / \mathrm{min}$, travel angle at 60 degrees, tip-to-work distance at $7 \mathrm{~mm}$, and shielded gas flow rate at 10 liters $/ \mathrm{min}$; see Figure 3. The maximum UTS calculated from (1) was $553 \mathrm{MPa}$.

3.5. Confirmation Test. To verify the multiple regression model in (1) and the optimization of welding parameters, six experiments used the optimal welding conditions. UTS obtained by the predicted model and the experiments were compared and percentage errors are shown in Table 5. The predicted UTS agreed well with the measured UTS. Deviations were between $-2 \%$ and $4 \%$.

Noticeably, the maximum UTS obtained from the experiment (558.3 MPa on average) was larger than the UTS of the base metal $(470 \mathrm{MPa})$. During tensile test, it was observed that tearing of welded specimen occurred at the weld joint rather than at the base metal. It was important to point out that high UTS could be obtained even when bead penetration was not completely full through the entire thickness of the workpiece.

\section{Conclusions}

We applied a fractional factorial design to zero-gap butt welding of mild steel using MAG. The study focused on the effect of welding parameters on the ultimate tensile strength (UTS) of the welded joint and the optimal welding conditions for maximum UTS. We conclude the following:

(1) Process parameters that showed the greatest to the least effects on UTS of welded joint were in the order of welding feed rate, tip-to-work distance, welding speed, welding voltage, and travel angle. Shield gas flow rate in the selected range was found to have little effect.

(2) UTS increased with increased welding feed rate, welding voltage, and travel angle. In contrast, UTS 
increased with decreased welding speed and tip-towork distance.

(3) The maximum UTS of a welded joint, $558 \mathrm{MPa}$ on average, was obtained at wire feed rate $=19 \mathrm{~m} / \mathrm{min}$ welding voltage $=30 \mathrm{~V}$, welding speed $=200 \mathrm{~mm} / \mathrm{min}$, travel angle $=60^{\circ}$, tip-to-work distance $=7 \mathrm{~mm}$, and shield gas flow rate $=10 \mathrm{~L} / \mathrm{min}$.

(4) Maximum UTS results from the regression model agreed with experiments within $4 \%$. Therefore, this model may be used to predict weld UTS with sufficient accuracy.

It is important to point out that the model obtained from this investigation is the first-order model in which only the main effect and the interaction terms are included. However, there is a possibility that the second-order model or a nonlinear model is more appropriate. Therefore, we plan to study response surface methods (RSM) to investigate process optimization.

\section{Conflict of Interests}

The authors declare that there is no conflict of interests regarding to the publication of this paper.

\section{Acknowledgments}

The authors thank Mahasarakham University and Rajamangala University of Technology Isan, Thailand, for supporting materials and equipment.

\section{References}

[1] S. Klarić, I. Samardžić, and I. Kladarić, "MAG welding process-analysis of welding parameter influence on joint geometry," in Proceedings of the 12th International Research/Expert Conference, p. 185, Istanbul, Turkey, August 2008.

[2] I. S. Kim, K. J. Son, Y. S. Yang, and P. K. D. V. Yaragada, "Sensitivity analysis for process parameters in GMA welding processes using a factorial design method," International Journal of Machine Tools and Manufacture, vol. 43, no. 8, pp. 763769, 2003.

[3] K. Y. Benyounis and A. G. Olabi, "Optimization of different welding processes using statistical and numerical approachesa reference guide," Advances in Engineering Software, vol. 39, no. 6, pp. 483-496, 2008.

[4] D. S. Correia, C. V. Gonçalves, S. S. C. Junior, and V. A. Ferraresi, "GMAW welding optimization using genetic algorithms," Journal of the Brazilian Society of Mechanical Sciences \& Engineering, vol. 26, no. 1, pp. 28-32, 2004.

[5] T. Cool, H. K. D. H. Bhadeshia, and D. J. C. MacKay, "The yield and ultimate tensile strength of steel welds," Materials Science and Engineering A, vol. 223, no. 1-2, pp. 186-200, 1997.

[6] P. Sathiya, M. Y. Abdul Jaleel, D. Katherasan, and B. Shanmugarajan, "Optimization of laser butt welding parameters with multiple performance characteristics," Optics and Laser Technology, vol. 43, no. 3, pp. 660-673, 2011.

[7] D. C. Montgomery, Design and Analysis of Experiments, John Wiley \& Sons, New York, NY, USA, 2001.
[8] M. H. Shojaeefard, A. Khalkhali, M. Akbari, and M. Tahani, "Application of Taguchi optimization technique in determining aluminum to brass friction stir welding parameters," Materials and Design, vol. 52, pp. 587-592, 2013.

[9] American Welding Society, "Welding processes, part 1," in Welding Handbook, vol. 2, pp. 148-205, American Welding Society, Miami, Fla, USA, 9th edition, 1991.

[10] Minitab, MINITAB Release 14-Stat Guide, Minitab, 20002003. 

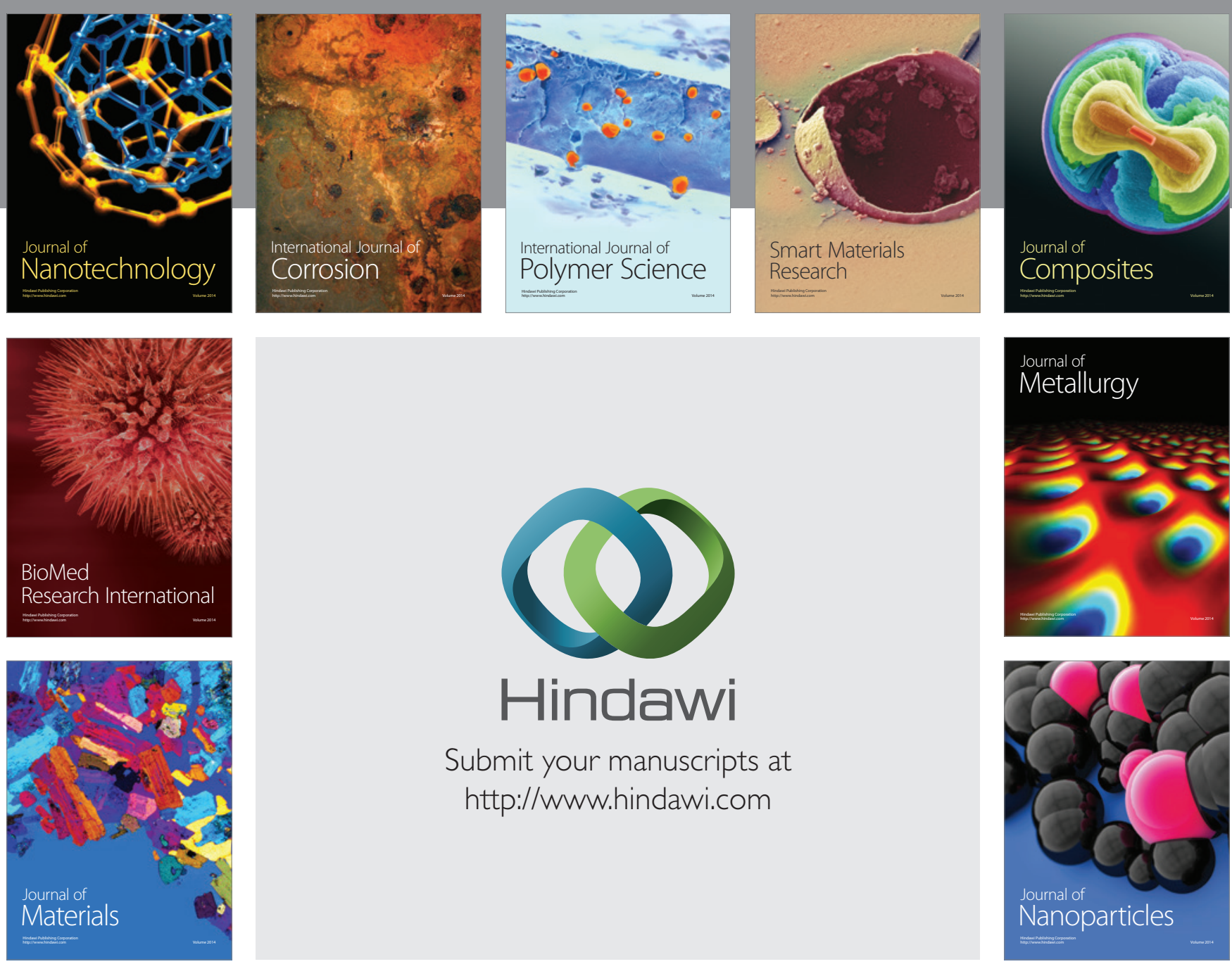

Submit your manuscripts at http://www.hindawi.com
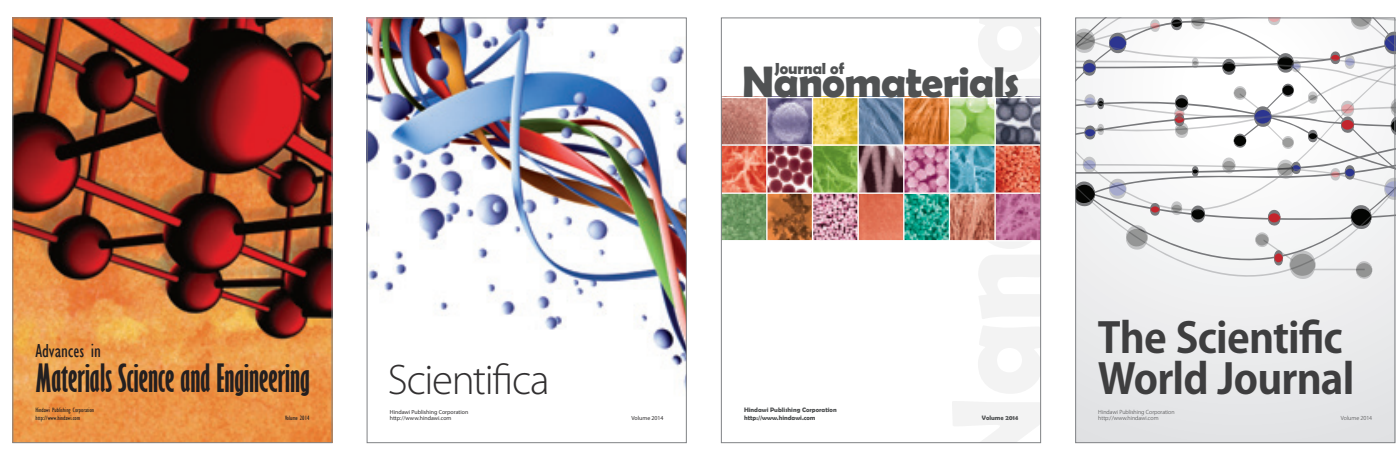

\section{The Scientific World Journal}
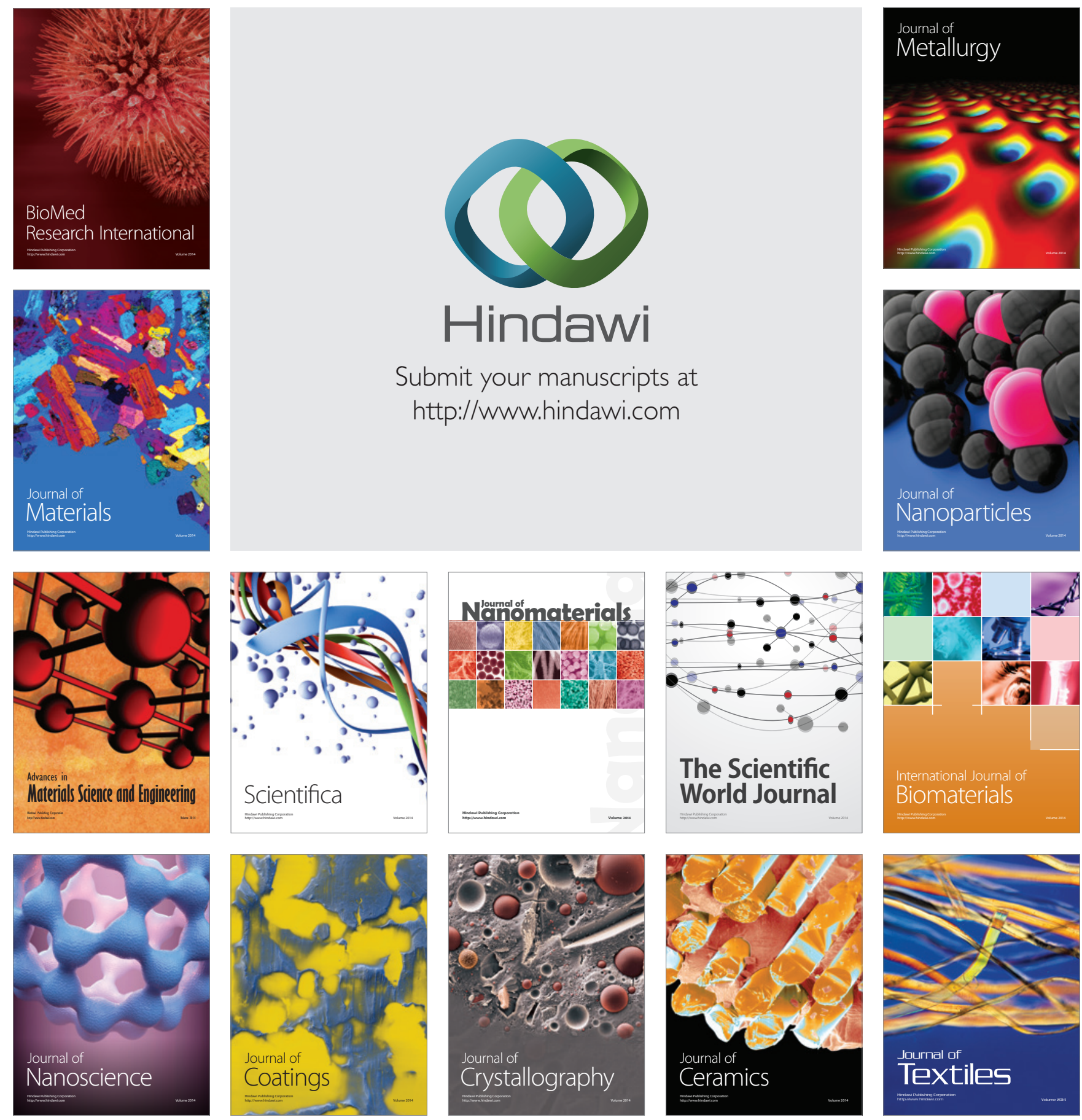